Document downloaded from:

http://hdl.handle.net/10251/149925

This paper must be cited as:

Pretel, R.; Robles Martínez, A.; Ruano García, MV.; Seco Torrecillas, A.; Ferrer, J. (2016). Economic and environmental sustainability of submerged anaerobic MBR based (AnMBRbased) technology compared to aerobic-based technologies for moderate-/high-loaded urban wastewater treatment. Journal of Environmental Management. 166:45-54. https://doi.org/10.1016/j.jenvman.2015.10.004

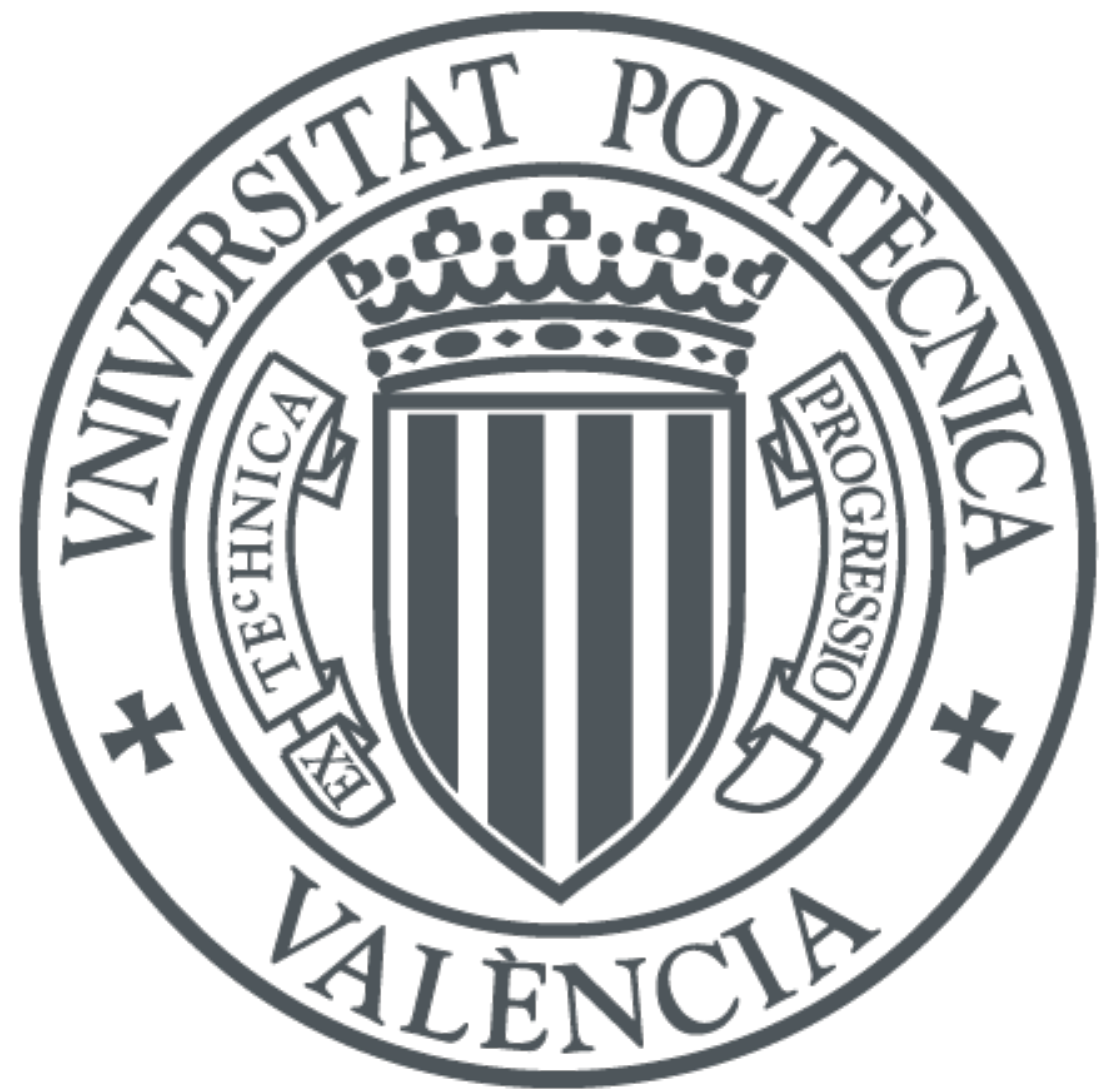

The final publication is available at

http://doi.org/10.1016/j.jenvman.2015.10.004

Copyright Elsevier

Additional Information 


\title{
Economic and environmental sustainability of submerged anaerobic MBR-based (AnMBR-based) \\ technology as compared to aerobic-based technologies for moderate-/high-loaded urban wastewater treatment
}

\author{
R. Pretel ${ }^{a, *}$, A. Robles ${ }^{a}$, M.V. Ruano ${ }^{b}$, A. Seco $^{b}$ and J. Ferrer ${ }^{a}$ \\ a Institut Universitari d'Investigació d'Enginyeria de l'Aigua i Medi Ambient, IIAMA, \\ Universitat Politècnica de València, Camí de Vera s/n, 46022 Valencia, Spain (e-mail: \\ rutprejo@upv.es; ngerobma@upv.es; jferrer@hma.upv.es) \\ b Departament d'Enginyeria Química, Escola Tècnica Superior d'Enginyeria, Universitat de \\ València, Avinguda de la Universitat s/n, 46100 Burjassot, Valencia, Spain (e-mail: \\ m.victoria.ruano@uv.es; aurora.seco@uv.es) \\ * Corresponding author: tel. +34 9638761 76, fax +34 9638790 09, e-mail: rutprejo@upv.es
}

\begin{abstract}
The objective of this study was to assess the economic and environmental sustainability of submerged anaerobic membrane bioreactors (AnMBRs) in comparison with aerobic-based technologies for moderate-/high-loaded urban wastewater (UWW) treatment. To this aim, a combined approach of steady-state performance modelling, life cycle analysis (LCA) and life cycle costing (LCC) was used, in which AnMBR (coupled with an aerobic-based post-treatment) was compared to aerobic membrane bioreactor (AeMBR) and conventional activated sludge (CAS). AnMBR with CAS-based post-treatment for nutrient removal was identified as a sustainable option for moderate-/high-loaded UWW treatment: low energy consumption and reduced sludge production could be obtained at given operating conditions. In addition, significant reductions can be achieved in different aspects of environmental impact (global warming potential (GWP), abiotic depletion, acidification, etc.) and LCC over existing UWW treatment technologies.
\end{abstract}

Keywords 
Global warming potential (GWP); life cycle analysis (LCA); life cycle costing (LCC); steadystate performance modelling; submerged anaerobic MBR (AnMBR).

\section{Introduction}

At the present time, meeting the requirements of urban wastewater (UWW) treatment (e.g. restrictions in effluent standards, treatment costs and spatial constraints) would best be met by alternative technologies rather than the traditional ones (e.g. conventional activated sludge (CAS)) (Gabarrón et al., 2015). Recent technological advances in wastewater treatment include membranes, in particular aerobic membrane bioreactors (AeMBR), which offer several advantages over traditional processes, including: high effluent quality, a small footprint and reduced sludge production (Judd \& Judd, 2011). However, although the market for MBR has recently been on the rise, the competitiveness of this technology is threatened by the low operating cost of CAS systems (Fenu et al., 2010). Current UWW treatment is mainly based on aerobic processes (i.e. CAS and AeMBR) in which a significant amount of power is required for aeration and the energy recovered from organic matter is not maximised (McCarty et al., 2011; Smith et al., 2014).

Using a submerged anaerobic membrane bioreactor (AnMBR) for UWW treatment reduces sludge production, eliminates aeration and generates methane (Giménez et al., 2011; Raskin, 2012; Smith et al., 2013). Although this technology still has not been applied to full-scale UWW treatment, recent publications (e.g. Ozgun et al, 2013; Raskin et al., 2012; Stuckey, 2012; Lin et al., 2011; Smith et al., 2014) have reported increasing interest in its use by the scientific community. 
Anaerobic processes are often operated at high temperatures in order to increase the microorganism growth rate, however AnMBRs have recently been shown to be able to treat UWW at lower temperatures (e.g. $15-20{ }^{\circ} \mathrm{C}$ ) (see, for instance, Giménez et al., 2011; Martinez-Sosa et al., 2011; Raskin, 2012). As the lower the temperature the higher the amount of methane dissolved in the effluent (Giménez et al., 2012), the possible emission of this dissolved methane into the atmosphere is a key issue in AnMBR technology. On the other hand, when this system is used nutrient removal is minimal (Visvanathan et al., 2000), so that when downstream treatment or alternative water reuse (e.g. irrigation) are not considered, the discharge of the nutrient-loaded AnMBR effluent can have a considerable environmental impact. Hence, one of the key concerns for sustainable UWW treatment by AnMBR is recovering the nutrients and methane from the effluent (Smith et al., 2014).

Mathematical models capable of predicting system performance under different design and operating scenarios could be useful tools for developing AnMBR systems. Ferrer et al. (2008) proposed the DESASS computational software for modelling different aerobic and anaerobic wastewater treatments, which they later updated to include AnMBR. The updated-version of this software incorporates the plant-wide mathematical model BNRM2 (Barat et al., 2012).

Ferrer et al. (2015) and Pretel et al. (2015a) established the basis of an economic framework (based on semi industrial-scale data and modelling) aimed at designing AnMBRs for full-scale UWW treatment by considering the key parameters affecting process performance. However, the selection of appropriate schemes for UWW treatment has to consider not only economic items (i.e. investment, operation and maintenance costs) but also environmental concerns (e.g. eutrophication, global 
warming potential (GWP), marine ecotoxicity, etc.). In this respect, the life cycle analysis (LCA) and life cycle costing (LCC) approaches have been recognised as useful for assessing the sustainability of different UWW treatment schemes (see e.g. Gallego et al., 2008; Foley et al., 2010; Rodriguez-Garcia et al., 2011; Godin et al., 2012; GarridoBaserba et al., 2013). Indeed, several studies have been published dealing with LCA applied to wastewater treatment, in compliance with Corominas et al. (2013). However, LCC and LCA applied to AnMBR for UWW treatment must be further evaluated and compared to the results from other wastewater treatment systems. Pretel et al. (2013), for instance, assessed the energy balance and LCA of an AnMBR system featuring industrial-scale membranes that treated UWW at different temperatures; whilst Pretel et al. (2015b) characterised the environmental impacts of design and operational decisions on AnMBR technology, as well as the resulting trade-offs across LCC and LCA frameworks.

The sustainability of AnMBR has recently been evaluated relative to alternative aerobic technologies (Smith et al., 2014). However, no references have been found that compared the sustainability of AnMBR coupled with downstream processes for nutrient removal with conventional treatment schemes. In view of this, the objective of the present study was to assess the economic and environmental sustainability of a possible AnMBR-based urban WWTP by combining steady-state performance modelling (using DESASS simulator software), LCA and LCC approaches. For this, AnMBR was compared to AeMBR and CAS applied to the removal of organic matter, nitrogen and phosphorus from moderate-/high-loaded UWW.

\section{Methodology}


The economic and environmental sustainability of an AnMBR-based WWTP (including an aerobic-based post-treatment for nutrient removal) was compared to three UWW treatment schemes based on CAS and AeMBR. All these treatment schemes were designed to meet the European discharge quality standards (sensitive areas and population of more than $100000 \mathrm{p}-\mathrm{e})$ as regards solids $\left(<35 \mathrm{mg} \cdot \mathrm{L}^{-1}\right.$ of TSS $)$, organic matter ( $<125$ and $25 \mathrm{mg} \cdot \mathrm{L}^{-1}$ of COD and BOD, respectively) and nutrients $(<10$ and 1 $\mathrm{mg} \cdot \mathrm{L}^{-1}$ of $\mathrm{N}$ and $\mathrm{P}$, respectively). In addition, a maximum value of $35 \%$ of biodegradable volatile suspended solids (BVSS) was established as the sludge stabilisation criterion. The study allowed for effluent disinfection either by filtration (in MBR-based systems) or ultraviolet (UV) radiation.

The three wastewater treatment systems (CAS, AeMBR and AnMBR) were designed and simulated using the updated version of the DESASS simulation software (Ferrer et al., 2008), which features the BNRM2 mathematical model (Barat et al., 2012). This mathematical model had previously been calibrated and validated for a wide range of operating conditions in an AnMBR system featuring industrial-scale membranes (Durán, 2013). DESASS enables the energy balance of different wastewater treatment schemes (including AnMBR systems) to be evaluated (Pretel et al., 2013).

For CAS and AeMBR, two different simulation scenarios were evaluated, according to the technology employed to reduce the phosphorus content in the influent: (1) chemical removal of phosphorus, or (2) combined biological and chemical removal of phosphorus. As in this case study the biological removal of phosphorus by itself was not enough to meet phosphorus effluent standards, the biological and chemical removal of phosphorus were combined in Scenario 2. For the AnMBR-based treatment scheme, only chemical removal of phosphorus was evaluated, since the acetic acid content in the 
AnMBR effluent was not high enough to justify biological removal of phosphorus in the downstream aerobic-based treatment unit.

\subsection{WWTP design and operation}

The evaluated wastewater treatment systems (i.e. CAS, AeMBR and AnMBR) were simulated at an ambient temperature of $20^{\circ} \mathrm{C}$. The treatment flow rate was set to 50000 $\mathrm{m}^{3} \cdot \mathrm{d}^{-1}$. The influent UWW used in this study was from the pre-treatment stage of the Carraixet WWTP (Valencia, Spain), a full characterisation of which is shown in Table 1a. This moderate-/high-loaded UWW had previously been used to obtain the experimental data related to the AnMBR unit evaluated in this study. Table $1 \mathrm{~b}$ shows the values of the main operating parameters established in CAS, AeMBR and AnMBR.

Figure 1 shows the process flow diagram of the proposed UWW treatment schemes evaluated in this study. The classical AO (anoxic - oxic) and A2O (anaerobic - anoxic oxic) configurations were selected for designing the aerobic-based treatment units in Scenarios 1 (chemical phosphorus removal) and 2 (biological and chemical phosphorus removal), respectively. The volume of anaerobic, anoxic and oxic tanks was defined as follows: 0, 40 and 60\% of total reactor volume in Scenario 1 and 40, 10 and 50\% of total reactor volume in Scenario 2, respectively. The ratio of nitrate being recycled into the influent flow was set to 4 times the influent flow. CAS and AeMBR included an anaerobic digestion (AD) unit in order to meet the sludge stabilisation criteria (see Figure 1).

In agreement with Judd \& Judd (2011), 2000 and 9000 ppm were adopted as the doses 
of sodium hypochlorite and citric acid, respectively, for membrane chemical cleaning in AeMBR units, whilst the chemical cleaning frequency was set to 12 months. The $20^{\circ} \mathrm{C}$ standardised transmembrane flux $\left(\mathrm{J}_{20}\right)$ was set to $14 \mathrm{~L} \cdot \mathrm{m}^{-2} \cdot \mathrm{h}^{-1}$ on the basis of the data reported by Judd \& Judd (2011) regarding industrial-scale AeMBRs (this selection accounted for the MLSS of the AeMBR unit: $\left.6.5 \mathrm{~g} \cdot \mathrm{L}^{-1}\right)$. Tertiary treatment was not required in AeMBR, since complete retention of the biomass was considered (i.e. membranes were considered tertiary treatment).

\section{$\underline{\text { AnMBR technology }}$}

As Table 1b shows, the mixed liquor suspended solids (MLSS) concentration in the AnMBR membrane tank was set to $14 \mathrm{~g} \cdot \mathrm{L}^{-1}$. For this MLSS, the $20^{\circ} \mathrm{C}$-standardised transmembrane flux $\left(\mathrm{J}_{20}\right)$ was set to $20 \mathrm{~L} \cdot \mathrm{m}^{-2} \cdot \mathrm{h}^{-1}$, while the specific gas demand per square metre of membrane area $\left(\mathrm{SGD}_{\mathrm{m}}\right)$ was set to $0.1 \mathrm{~m}^{3} \cdot \mathrm{m}^{-2} \cdot \mathrm{h}^{-1}$. These $\mathrm{J}_{20}$ and $\mathrm{SGD}_{\mathrm{m}}$ values were selected on the basis of previous experimental results obtained in an AnMBR system fitted with industrial-scale hollow-fibre membranes (Robles et al., 2012). This MLSS- $\mathbf{J}_{20}-S_{G D}$ combination corresponded to the filtration conditions around the critical ones ( $\mathrm{J}_{20}$ of around $105 \%$ of the experimentally-determined critical flux), since this operating mode had been shown to give minimum filtration costs in previous studies (Ferrer et al., 2015; Pretel et al., 2015a).

Since AnMBR is still not a mature technology, a basic uncertainty analysis was carried out on $\mathrm{SGD}_{\mathrm{m}}$ and $\mathrm{J}_{20}$. The effect of varying the operating $\operatorname{SGD}_{\mathrm{m}}\left(0.05\right.$ and $0.30 \mathrm{~m}^{3} \cdot \mathrm{m}^{-}$ $\left.{ }^{2} \cdot \mathrm{h}^{-1}\right)$ and $\mathrm{J}_{20}\left(80\right.$ and $120 \%$ of the critical flux, corresponding to 15 and $22 \mathrm{~L} \cdot \mathrm{m}^{-2} \cdot \mathrm{h}^{-1}$, respectively) was assessed and compared to the baseline evaluated in this study (SGDm of $0.10 \mathrm{~m}^{3} \cdot \mathrm{m}^{-2} \cdot \mathrm{h}^{-1}$ and $\mathrm{J}_{20}$ of $105 \%$ of the critical flux). 
Following Judd \& Judd (2011) and other studies (see, for instance, Robles et al., 2012), 7.5 months was set as the interval for membrane chemical cleaning when operating at $\mathbf{J}_{20}$ around $105 \%$ of critical flux. In compliance with the manufacturer's recommendations, $2000 \mathrm{ppm}$ was adopted as the dose of both sodium hypochlorite and citric acid for chemical cleaning of the membranes.

A post-treatment step based on AO (anoxic - oxic) configuration with the addition of chemicals for phosphorus removal was included in the AnMBR-based treatment scheme in order to meet nutrient effluent standards. This step considered two possibilities: AeMBR-based and CAS-based post-treatment. Table 1c gives the values selected for the main operating parameters in both configurations. The membrane cleaning protocol adopted for the AeMBR-based post-treatment was the same as the one proposed in AeMBR. The MLSS in the AeMBR unit used as post-treatment was $2.6 \mathrm{mg} \cdot \mathrm{L}^{-1}$, which is low compared with the MLSS when used as the main treatment in AeMBR (MLSS of $\left.6.5 \mathrm{~g} \cdot \mathrm{L}^{-1}\right)$. This means that higher fluxes can be set in the AeMBR than in AeMBR when used as post-treatment (Judd \& Judd, 2011). $\mathrm{J}_{20}$ was thus set to $29 \mathrm{~L} \cdot \mathrm{m}^{-2} \cdot \mathrm{h}^{-1}$.

Two different scenarios were evaluated in the AnMBR-based treatment scheme according to the fate of the methane dissolved in the effluent: this was either (a) captured for energy production (using a degassing membrane for separation); or (b) used as the source of organic matter for denitrification in the corresponding posttreatment unit. A fraction of the influent wastewater was bypassed to the post-treatment unit in order to meet effluent quality standards (additional organic matter was required for denitrification to that contained in the AnMBR effluent). Around 27 and 16\%, respectively, of the wastewater entering the AnMBR-based WWTP was diverted directly to the post-treatment unit when the dissolved methane was used for energy 
production and denitrification. Four different scenarios were therefore considered in AnMBR, according to the fate of the methane dissolved in the effluent and the posttreatment considered: AnMBR+AeMBR and AnMBR+CAS when the dissolved methane was used for energy production, and AnMBR+AeMBR $\mathrm{CH}_{4 \mathrm{DN}}$ and AnMBR + CAS ${ }_{C H 4 D N}$ when the dissolved methane was used for denitrification. Further digestion of the sludge was not required in AnMBR, since this unit had already been designed to meet the sludge stabilisation criteria.

\subsection{LCC implementation}

The total annualised equivalent cost was calculated by adding the annual investment cost (considering a discount rate of $10 \%$ and a project lifetime of 20 years) to the annual operating and maintenance costs.

The investment cost included construction work for concrete structures (primary and secondary settler, anaerobic reactor, $\mathrm{AO} / \mathrm{A} 2 \mathrm{O}$ reactors, membrane tank, anaerobic digester, CIP (clean-in-place) tank, thickener, and equalisation tank) and equipment (pumps and blowers, piping and valve system, aeration devices (diffusers) and their supports, air cleaning equipment, stirrers, rotofilter, dewatering system, ultrafiltration hollow-fibre membranes, circular suction scraper bridges for the primary and secondary settler and thickener, UV radiation system, combined heat and power (CHP), degassing membrane system and the required area of land). Construction work and equipment was different for each system evaluated (see Table 2).

Although a degassing membrane system was considered for complete recovery of the methane dissolved in the effluent, it is important to note that this system still has not 
been optimised. In this respect, further development of efficient dissolved methane recovery is needed in order to both maximise energy recovery and avoid direct greenhouse gas emissions.

The operating and maintenance costs consisted of: heat requirements for maintaining a temperature of $35^{\circ} \mathrm{C}$ in the $\mathrm{AD}$ unit in $\mathrm{AeMBR}$ and $\mathrm{CAS}$, power requirements, energy recovery from methane capture, chemical reagents used for membrane cleaning (in AnMBR and AeMBR), chemical reagents for diffuser cleaning, $\mathrm{FeCL}_{3}$ dosage for chemical removal of phosphorus, and sludge handling and disposal, including a dewatering system and polyelectrolyte consumption. Maintenance expenditure included the replacement of pumps and blowers, stirrers, rotofilter, air diffusers for the aeration system, and lamps for UV disinfection when necessary. The power requirements consisted of: air pumping (for removing organic matter and/or nitrification), membrane scouring by air/gas sparging, permeate pumping, the rest of the pumping system (sludge recirculation in bioreactor, influent pumping, waste sludge pumping, etc.), anaerobic digester/ reactor stirring, $\mathrm{AO} / \mathrm{A} 2 \mathrm{O}$ reactor stirring, rotofilter, settling, sludge thickening and dewatering and UV radiation.

Table S1 (Supplementary Data) shows the unit costs used to calculate the capital and operating expenses (CAPEX/OPEX) of the proposed treatment systems. Further details of the LCC methodology used in this study can be found in Ferrer et al. (2015) and Pretel et al. (2015a).

\subsection{LCA implementation}

LCA methodology is subdivided into four stages (ISO, 2006): (1) goals and scope of the 
study, in which the definition of the activity, the purpose of the study, the functional unit, the system boundaries, and the method employed are established; (2) life cycle inventory (LCI), including the list of inputs (energy use and material sourcing) and outputs (emissions to atmosphere, water and soil); (3) life cycle impact assessment (LCIA), which evaluates the environmental impact of the environmental resources and releases identified during the LCI (comprising, among others, selection and definition of impact categories, classification, characterisation and normalisation); and (4) the interpretation of the results.

The goal of this study was to evaluate the environmental impact of different UWW treatment schemes associated with both water line operation (primary and secondary UWW treatment, and final discharge of the treated effluent) and sludge treatment (reduction of the organic matter content in the sludge to comply with the established stabilisation criteria). A functional unit based on the volume of treated wastewater $\left(\mathrm{m}^{3}\right)$ was used for the comparison of the different UWW treatment schemes.

The LCA framework was implemented according to ISO 14040 (2006). The life cycle inventories (LCI) of individual materials and processes were compiled using the Ecoinvent Database v.3 accessed via SimaPro 8.03 (PRé Consultants; The Netherlands). The Centre of Environmental Science (CML) 2 baseline 2000 methodology was used to conduct the impact assessment. The impact categories considered in this study were: eutrophication (quantified as $\mathrm{kg} \mathrm{PO}_{4}$ eq.), global warming potential with a 100-year time horizon (GWP100; quantified as $\mathrm{kg} \mathrm{CO}_{2}$ eq.), abiotic depletion (quantified as $\mathrm{kg}$ Sb eq.), marine aquatic ecotoxicity (quantified as $\mathrm{kg}$ 1,4-DB eq.), and acidification (quantified as $\mathrm{kg} \mathrm{SO}_{4}$ eq.). 


\section{System boundaries}

The following system boundaries were considered:

Construction, operation and demolition phase (materials recycled or disposal to landfill), as well as the transport of materials, reagents and sludge (assuming a distance for transport of $10 \mathrm{~km}$ ) were included within the system boundary. Concrete structures and pipes were excluded from the demolition phase because their useful life was longer than the lifetime of the project itself.

A useful membrane lifetime of 20 years was assumed, according to the total chlorine contact specified by the manufacturer (see Table S1) and the membrane chemical cleaning frequency laid down.

Pre-treatment processes (e.g. screening, degritting, and grease removal) were not included in this study because they were assumed to feature in all the evaluated systems.

The waste sludge was disposed of as follows: $80 \%$ to agricultural application, $10 \%$ to landfill and 10\% to incineration (Spanish Ministry of Agriculture, Food and Environment, 2015).

$\mathrm{CO}_{2}$ emissions from sludge dewatering and biogas capture were not taken into account because $\mathrm{CO}_{2}$ is classified as biogenic according to IPCC guidelines (Hobson, 2000).

The biogas and methane dissolved in the effluent stream were considered to be totally recovered and used for energy production, so that no fugitive methane emissions into the atmosphere were considered when evaluating climatic implications. The cost of both the degassing membrane for dissolved methane recovery and microturbine-based CHP technology for energy generation were also 
considered.

Emissions to air (e.g. $\mathrm{CO}, \mathrm{SO}_{2}, \mathrm{NO}_{2}$, non-methane volatile organic compounds) from biogas combustion (through microturbine-based CHP) were excluded due to a lack of information.

Table S2 (Supplementary Data) shows the inventory data and the parameters used in the LCA study, including the Ecoinvent process and substances extracted from SimaPro 8.03. Six main factors were considered when determining the environmental performance of the evaluated treatment schemes: (1) energy consumption; (2) energy recovery from methane (biogas and dissolved methane capture); (3) consumption of chemical reagents $\left(\mathrm{FeCl}_{3}\right.$, polyelectrolyte, $\mathrm{NaOCl}$ and citric acid); (4) employment of construction materials (concrete, iron, chromium steel, polyester and epoxy resin, polypropylene, glass tube, etc.); (5) final discharge of the effluent; and (6) sludge disposal including emissions.

\section{Results and discussion}

\subsection{Energy balance}

Figure 2 gives the energy balance of CAS, AeMBR and AnMBR (AnMBR+AeMBR, AnMBR+AeMBR ${ }_{\mathrm{CH} 4 \mathrm{DN}}, \mathrm{AnMBR}+\mathrm{CAS}$, and AnMBR+CAS $\left.{ }_{\mathrm{CH} 4 \mathrm{DN}}\right)$, including both power requirements and energy production.

As can be seen in Figure 2, the power requirements for air pumping (organic matter removal and/or nitrification) accounted for the largest percentage of total power requirements (up to $49 \%$ ) in all the proposed treatment schemes, except in those that 
included an AeMBR unit. In these cases, membrane scouring by air sparging (up to $46 \%$ ) became the largest percentage of the total power requirement. For the two scenarios including an AeMBR-based post-treatment unit (AnMBR+AeMBR and AnMBR+AeMBR ${ }_{\mathrm{CH} 4 \mathrm{DN}}$ ), membrane scouring by air sparging and air pumping for nitrification both showed similar percentages (around 28 and 25\%, respectively). CAS needed considerable power requirements related to reactor stirring (around 29\%). With regard to AnMBR schemes, all the proposed scenarios had significant power requirements as regards membrane scouring by biogas sparging and anaerobic reactor stirring (both processes consumed up to $19 \%$ of total power requirements).

In absolute terms, AeMBR had high power requirements, with a value of $0.84 \mathrm{kWh} \cdot \mathrm{m}^{-3}$ in Scenario 1 (biological and chemical removal of phosphorus) and $0.81 \mathrm{kWh} \cdot \mathrm{m}^{-3}$ in Scenario 2 (chemical removal of phosphorus). It is important to note that this technology requires air for both membrane scouring and organic matter removal (air pumping). On the other hand, power requirements were low in AnMBR+CAS and AnMBR+CAS ${ }_{\mathrm{CH} 4 \mathrm{DN}}$, with a value of 0.48 and $0.46 \mathrm{kWh} \cdot \mathrm{m}^{-3}$, respectively. These low values were the result of avoiding a secondary MBR-based process for nutrient removal (i.e. power was not required for membrane scouring by air sparging).

As regards phosphorus removal, Figure 2 shows that the power requirements for biological and chemical removal of phosphorus (Scenario 1) were relatively similar to those for chemical removal (Scenario 2). In this respect, although chemical removal of phosphorus produced higher amounts of sludge (thus increasing energy consumption for sludge thickening and dewatering), the biological removal of phosphorus consumed more energy for air pumping and reduced the energy recovery potential (a fraction of the organic matter was consumed by polyphosphate-accumulating organisms, thus 
reducing the directly-available COD for methanisation). However, power requirements for nitrogen and phosphorus removal were evidently higher than those for nitrogen removal (data not shown). It should be remembered that biological phosphorus removal enables nutrient recovery by applying the appropriate downstream processes (e.g. struvite crystallization).

As regards power energy recovery by methane capture, AeMBR had the highest energy demand, since it did not produce enough biogas to meet its high power requirements. The highest power energy recovery potential (around $0.45 \mathrm{kWh} \cdot \mathrm{m}^{-3}$ ) was that of AnMBR+AeMBR and AnMBR+CAS, as the methane dissolved in the effluent was used to produce energy. Nevertheless, although AnMBR+AeMBR ${ }_{\mathrm{CH} 4 \mathrm{DN}}$ and AnMBR+CAS ${ }_{C H 4 D N}$ used the methane dissolved in the AnMBR effluent for denitrification in the AeMBR- and CAS-based post-treatment units, both schemes had a similar power energy recovery potential $\left(0.43 \mathrm{kWh} \cdot \mathrm{m}^{-3}\right)$ to AnMBR+AeMBR and AnMBR+CAS. In AnMBR+AeMBR and AnMBR+CAS it was necessary to bypass a higher fraction of the influent flow to the post-treatment unit for denitrification than when using the dissolved methane for this purpose. Thus, methane production was reduced in the AnMBR unit due to the smaller amount of organic matter directly available for methanisation.

It should be noted that a net heat energy demand was needed in AeMBR ( 0.06 and 0.02 $\mathrm{kWh} \cdot \mathrm{m}^{-3}$ in Scenarios 1 and 2, respectively) and CAS $\left(0.05\right.$ and $0.03 \mathrm{kWh} \cdot \mathrm{m}^{-3}$ in Scenarios 1 and 2, respectively) to maintain a temperature of $35^{\circ} \mathrm{C}$ in the $\mathrm{AD}$ unit. This heat energy increased the total energy demand in these configurations. 
The net energy demand for nutrient removal (considering energy recovery from methane) of the evaluated treatment schemes was (see Figure 2): 0.56 and $0.50 \mathrm{kWh} \cdot \mathrm{m}^{-}$ ${ }^{3}$ for AeMBR in Scenarios 1 and 2, respectively; 0.23 and $0.21 \mathrm{kWh} \cdot \mathrm{m}^{-3}$ for CAS in Scenarios 1 and 2, respectively; $0.20 \mathrm{kWh} \cdot \mathrm{m}^{-3}$ for AnMBR+AeMBR and AnMBR+AeMBR ${ }_{\mathrm{CH} 4 \mathrm{DN}} ; 0.04 \mathrm{kWh} \cdot \mathrm{m}^{-3}$ for AnMBR+CAS; and $0.03 \mathrm{kWh} \cdot \mathrm{m}^{-3}$ for

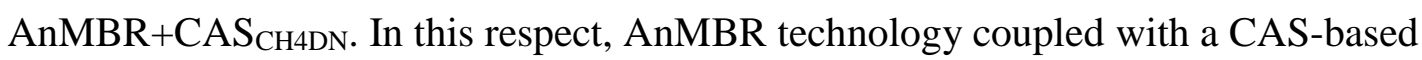
post-treatment for nutrient removal at $20{ }^{\circ} \mathrm{C}$ would have almost no energy demands for the operating conditions studied. A theoretical minimum energy consumption of around $0.04 \mathrm{kWh} \cdot \mathrm{m}^{-3}$ could be achieved by capturing the methane from both biogas and effluent.

It is interesting to note that the influent UWW presents a high BOD concentration (715 $\mathrm{mg} \cdot \mathrm{L}^{-1}$ ), so that a higher amount of biodegradable organic matter is anaerobically converted into methane than when treating low-loaded UWW. These conditions thus favour the economic sustainability of AnMBR technology, since more energy is generated from methane capture.

\subsection{Life cycle costs}

Figure 3 shows the total cost (divided into capital and operating and maintenance (O\&M) costs) of CAS, AeMBR and AnMBR (AnMBR+AeMBR, $A n M B R+A e M B R_{C H 4 D N}, A n M B R+C A S$ and $\left.A n M B R+C A S_{C H 4 D N}\right)$ for nutrient removal. Note that the bars in Figure 3 represent the results obtained (applying a discount rate of $10 \%$ ) when $80 \%$ of the waste sludge was destined to agricultural application, $10 \%$ to landfill and $10 \%$ to incineration. The results shown in this figure when the $100 \%$ of 
waste sludge was destined to these purposes are labelled by triangles, rhombi and squares, respectively. The total cost was also evaluated for the case of applying a discount rate of $5 \%$ (represented by a horizontal line in Figure 3).

AeMBR showed the highest life cycle cost (expressed as total annualised equivalent cost, $€$ per $\mathrm{m}^{3}$ in Figure 3 ) due to its significant operational costs, mainly associated with the power required for aeration and membrane scouring. CAS had the lowest capital cost, since membrane investment was zero and the cost of the concrete structures was not significantly important. In spite of the membrane investment cost, AnMBR+CAS and $\mathrm{AnMBR}+\mathrm{CAS} \mathrm{SH}_{\mathrm{CHN}}$ both showed lower life cycle costs than CAS, since more energy was recovered from methane capture. AnMBR+AeMBR and AnMBR+AeMBR ${ }_{C H 4 D N}$ had higher life cycle costs than CAS (even though operating cost were similar) as the membrane investment cost in both AeMBR and AnMBR significantly increased total capital costs.

The sludge handling and disposal practice was a key factor in the life cycle cost of the evaluated UWW treatment schemes. As commented above, total life cycle costs were also calculated assuming that $100 \%$ of the waste sludge was to be disposed of by a single method (agricultural application, landfill or incineration) (see Figure 3). Sludge used as fertiliser (agricultural application) or in landfill had a much lower life cycle cost than when incinerated. These results were mainly based on the costs attributed to the above three disposal methods (€4.8, €250.0 and €30.1 per t TSS, respectively) (see Table S1). A reduction in total cost of around $30 \%$ can be achieved when the discount rate is reduced from 10 to $5 \%$, as can be seen in Figure 3. 
As regards phosphorus removal, Figure 3 shows that the life cycle costs for biological and chemical removal of phosphorus (Scenario 1) were fairly similar to those of chemical removal of phosphorus (Scenario 2).Even though lower chemical consumption (reducing its associated cost), less sludge production (lower sludge handling and disposal costs) and lower energy stirring costs (since the anoxic tank represented only $10 \%$ of the total reaction volume) were obtained in Scenario 1, Scenario 2 had lower costs related to reduced air pumping, higher energy recovery potential and lower reacting volumes.

The life cycle costs of the evaluated treatment schemes for nutrient removal were (see Figure 3): $€ 0.198$ and $€ 0.192$ per $\mathrm{m}^{3}$ for AeMBR in Scenarios 1 and 2, respectively; $€ 0.169$ per $^{3}$ for AnMBR+AeMBR; $€ 0.165$ per $\mathrm{m}^{3}$ for $\mathrm{AnMBR}+\mathrm{AeMBR} \mathrm{CH}_{4 \mathrm{DN}} ; € 0.140$ and $€ 0.141$ per $\mathrm{m}^{3}$ for CAS in Scenarios 1 and 2 , respectively; $€ 0.135$ per $\mathrm{m}^{3}$ for AnMBR+CAS; and $€ 0.126$ per $\mathrm{m}^{3}$ for $\mathrm{AnMBR}+\mathrm{CAS} \mathrm{CH}_{\mathrm{CHN}}$.

It can therefore be concluded that from an economic perspective, AnMBR+CAS at 20 ${ }^{\circ} \mathrm{C}$ would be a more sustainable approach for moderate-/high-loaded UWW treatment than other systems at present in existence. AnMBR+AeMBR life cycle costs can be expected to increase by up to 17 and $23 \%$ when compared to CAS and AnMBR+CAS, respectively. However, it is important to remember that AeMBR-based post-treatments could become an interesting alternative to CAS processes when water reuse is included (e.g. for industrial purposes), since a high-quality effluent with nearly complete absence of pathogenic bacteria can be achieved.

Different $\mathrm{SGD}_{\mathrm{m}}$ and $\mathrm{J}_{20}$ values were assessed in the AnMBR system to compare its economic sustainability with the other systems studied. Figure 4 illustrates the effect of 
varying the operating $\operatorname{SGD}_{\mathrm{m}}\left(0.05\right.$ and $\left.0.30 \mathrm{~m}^{3} \cdot \mathrm{m}^{-2} \cdot \mathrm{h}^{-1}\right)$ and $\mathrm{J}_{20}(80$ and $120 \%$ of the critical flux) on the AnMBR total cost.

Comparing the AnMBR baseline ( $\mathrm{SGD}_{\mathrm{m}}$ of $0.10 \mathrm{~m}^{3} \cdot \mathrm{m}^{-2} \cdot \mathrm{h}^{-1}$ and $\mathrm{J}_{20}$ of $105 \%$ of critical flux) with the scenario operating at $\mathrm{J}_{20}$ of 80 and $120 \%$ of the critical flux, the AnMBR life cycle cost increases to 17 and $66 \%$, respectively (see Figure 4). However, a considerable increase in life cycle cost is observed when operating at $\mathbf{J}_{20}$ of $120 \%$ of the critical flux. Although increasing the operating flux reduces investment cost (i.e. smaller required membrane filtration area), there is a greater fouling propensity, which means a higher chemical cleaning frequency. This in turn raises the chemical reagent consumption (i.e. increased reagent cost) while membrane lifetime is reduced (i.e. increased membrane replacement cost). However, when operating at an $\mathrm{SGD}_{\mathrm{m}}$ of 0.05 and $0.30 \mathrm{~m}^{3} \cdot \mathrm{m}^{-2} \cdot \mathrm{h}^{-1}$ the life cycle cost increases to 10 and $20 \%$, respectively. Hence, the current aerobic-based technologies may become more sustainable than AnMBR if nonoptimum values are applied for the different AnMBR design parameters.

\subsection{Life cycle analysis}

As has already been mentioned, SimaPro software was used with Ecoinvent data to assess the potential environmental impact of the evaluated UWW treatment schemes.

\subsubsection{Life cycle inventory assessment}

The environmental impacts of the factors considered in the inventory analysis (see Table S2) and the impact categories selected in this study (i.e. marine aquatic ecotoxicity, GWP, abiotic depletion, acidification and eutrophication) are discussed in 
the following paragraphs. These results are based on the LCA results obtained from the proposed treatment schemes and scenarios. Figure 5 shows the life cycle inventory assessment for the following impact categories: marine aquatic ecotoxicity, GWP, abiotic depletion and acidification.

\section{Marine aquatic ecotoxicity}

As can be seen in Figure 5a, the environmental impact in this category was mostly associated with sludge disposed of as landfill (with a value of $43 \pm 5 \%$; average \pm standard deviation) and $\mathrm{FeCl}_{3}$ consumption for chemical phosphorus removal (with a value of $33 \pm 6 \%$ ). This behaviour was similar for all the schemes evaluated. The next in importance were energy consumption (with a value of $9 \pm 6 \%$ ), sludge used as fertiliser for agriculture (associated with heavy metal emissions to soil) (with a value of $12 \pm 1 \%$ ), and use of materials for construction and equipment (concrete, iron, chromium steel, etc, with a value of $4 \pm 1 \%$ ). Consumption of polyelectrolyte and membrane cleaning reagents had barely any environmental impact in comparison with the other factors. Note that the fertiliser avoided had a positive environmental impact, since the use of synthetic fertiliser for agriculture was partially avoided (see Figure 5a).

\section{$\underline{G W P}$}

The results in this impact category (see Figure 5b) were mostly associated with energy consumption (with a value of $42 \pm 20 \%$ ), followed to a lesser extent by: emissions to air (e.g. $\mathrm{N}_{2} \mathrm{O}$ ) when waste sludge was used for landfill or agricultural application (with a value of $35 \pm 12 \%$ ); chemical consumption (mainly $\mathrm{FeCl}_{3}$ for chemical phosphorus removal, with a value of $15 \pm 7 \%$ ); and use of materials for construction and equipment (concrete, iron, chromium steel, etc., with a value of $6 \pm 3 \%$ ). In AeMBR, the environmental impact related to energy consumption was higher than that related to 
sludge disposal, since considerable energy was required in this treatment scheme, unlike AnMBR and CAS. Also in this case, polyelectrolyte and membrane cleaning reagent consumption had barely any environmental impact as compared to the other factors. Note that the fertiliser avoided gave a positive environmental impact through GWP, since by its use less synthetic fertiliser was needed (see Figure 5b).

\section{$\underline{\text { Abiotic depletion }}$}

Energy consumption (with a value of $37 \pm 21 \%)$ and chemical consumption $\left(\mathrm{FeCl}_{3}\right.$ and polyelectrolyte, with a value of $42 \pm 16 \%$ ) (see Figure 5c) were the factors that affected abiotic depletion most. Environmental impact values in AeMBR related to energy consumption were higher than those for $\mathrm{FeCl}_{3}$ consumption, unlike AnMBR and CAS. The next in importance were: use of materials for construction and equipment (concrete, iron, chromium steel, etc., with a value of $7 \pm 3 \%$ ) and disposal of waste sludge (with a value of $4 \pm 1 \%$ ). Consumption of reagents for membrane cleaning had barely any environmental impact in this category compared to the other factors. Note that the fertiliser avoided had a significantly higher positive environmental impact in this than in the other impact categories.

\section{$\underline{\text { Acidification }}$}

Using waste sludge as fertiliser for agriculture had the highest environmental impact through acidification (mainly due to $\mathrm{NH}_{3}$ emissions). The remaining factors had hardly any environmental impact.

\section{Eutrophication}

Eutrophication is considered the most important impact category in most of the published LCAs on WWTPs (Rodriguez-Garcia et al., 2011). In the present study, 
effluent discharge (nitrogen, phosphorus and organic matter) was the factor that affected eutrophication most (around $80 \%$ in every treatment scheme and scenario), followed to a lesser extent by sludge used as fertiliser in agriculture (around 20\%), mainly due to $\mathrm{PO}_{4}{ }^{3-}$ leakage and $\mathrm{NH}_{3}$ emissions associated with this practice.

\subsubsection{Overall inventory results}

Figure 6 gives the LCA results of the impact categories evaluated in this study (i.e. GWP, eutrophication, marine aquatic ecotoxicity, abiotic depletion and acidification). The values shown in Figure 6a were weighted (based on normalised values per $\mathrm{m}^{3}$ ) to assess the magnitude of each impact category on the different treatment schemes and scenarios by applying a value of $100 \%$ to the configuration (scheme and scenario) that had the highest environmental impact.

As can be seen in Figure 6a, marine aquatic ecotoxicity was considered the most important impact category in all the evaluated UWW treatment schemes, since the characterised factors in this category (for $\mathrm{Fecl}_{3}$ consumption, sludge production, energy consumption, etc.) are generally higher than those of other impact categories. The next in importance was eutrophication. It should be noted that although the treatment schemes were designed to meet the European discharge quality standards, the remaining nutrient and organic matter content in the effluent noticeably affected eutrophication. Although GWP, abiotic depletion and acidification were among the less important impact categories, they are usually regarded as important environmental issues, at least from a political and social point of view. In this respect, the complexity of environmental issues combined with social and political challenges shows the need for a better understanding of the many factors that affect categories such as GWP, abiotic 
depletion and acidification.

AeMBR had the highest environmental impact values in GWP, abiotic depletion and acidification (see Figure $6 \mathrm{~b}$ ). As mentioned earlier, the high sludge production and energy demand of this treatment scheme had a considerable negative effect on these three impact categories. CAS presented the highest environmental impact in marine aquatic toxicity, since this treatment scheme had the highest $\mathrm{FeCl}_{3}$ consumption.

AnMBR gave the lowest environmental impact in all the evaluated impact categories, except eutrophication. For CAS, the environmental loads of GWP, abiotic depletion and acidification were 10, 25 and 5\% lower, respectively, than those obtained in AeMBR when removing phosphorus chemically. The AnMBR configuration featured the highest environmental impact in eutrophication, since the nitrogen content in the discharged effluent was slightly higher than in the other configurations (around $9 \mathrm{mg} \cdot \mathrm{L}^{-1}$ ). However, the environmental loads of GWP, abiotic depletion, marine aquatic ecotoxicity and acidification of AnMBR were 52, 42, 15 and 11\% lower, respectively, than those in AeMBR when removing phosphorus chemically. Note that AnMBR had the lowest sludge production and energy demand. In addition, AnMBR coupled to a CAS-based rather than AeMBR-based post-treatment showed reduced environmental impact values (mainly in GWP and abiotic depletion) mostly because of the latter's higher energy demand.

The contribution of the treatment schemes for nutrient removal to the eutrophication impact were thus, in descending order (see Figure 6b): AnMBR+CAS ${ }_{\mathrm{CH} 4 \mathrm{DN}}$, AnMBR+CAS, AnMBR+AeMBR ${ }_{\mathrm{CH} 4 \mathrm{DN}}, \mathrm{AnMBR}+\mathrm{AeMBR}, \mathrm{CAS}, \mathrm{AeMBR}$. The treatment schemes for nutrient removal contributing to marine aquatic toxicity were, in 
descending order (see Figure 6b): CAS, AeMBR, AnMBR+AeMBR ${ }_{\mathrm{CH} 4 \mathrm{DN}}$, AnMBR+AeMBR, AnMBR+CAS ${ }_{\mathrm{CH} 4 \mathrm{DN}}$, and AnMBR+CAS. The schemes contributing to the other impact categories (GWP, abiotic depletion and acidification) were, in descending order (see Figure 6b): AeMBR, CAS, AnMBR+AeMBR ${ }_{\mathrm{CH} 4 \mathrm{DN}}$, AnMBR+AeMBR, AnMBR+CAS ${ }_{\mathrm{CH} 4 \mathrm{DN}}$, and AnMBR+CAS.

Hence, from an environmental perspective, AnMBR could be considered a promising sustainable alternative for moderate-/high-loaded UWW treatment in comparison with the systems at present in use. Another important consideration is that in AnMBR systems the nutrients from the treated effluent could be used for fertigation (i.e., irrigation with nutrient-rich water) instead of using an aerobic-based (e.g. CAS) posttreatment for nutrient removal. AnMBR without post-treatment (using the nutrients from the treated effluent for fertigation) could significantly reduce its life cycle cost as savings of up to $42 \%$ can be achieved, mostly in operating costs. This would improve environmental impact values (reductions of up to $53 \%$ could be reached in GWP) as a result of: reduced fertiliser use due to fertigation, lower energy consumption, and the non-use of $\mathrm{FeCl}_{3}$. By using electricity produced on site, energy offsets of $0.12 \mathrm{kWh}$ per $\mathrm{m}^{3}$ can be achieved in AnMBR systems (under the scenarios evaluated in this study) when a post-treatment unit for nutrient removal is not required.

It should be emphasise that the results obtained in this study are strongly dependent on UWW characteristics, operating temperature and methane recovery potential, among other factors. However, AnMBR technology for UWW treatment has been shown to have improved sustainability when treating high-loaded UWW at warm/hot temperatures (Pretel et al., 2013; Smith et al., 2014). 


\section{Conclusions}

AnMBR technology was compared to aerobic-based UWW treatment technologies by combining the steady-state performance modelling, LCA and LCC approaches. AnMBR with a CAS-based post-treatment for nutrient removal was identified as a sustainable option for moderate-/high-loaded UWW treatment: a minimum energy consumption of $0.04 \mathrm{kWh} \cdot \mathrm{m}^{-3}$ and low sludge production could be obtained under given operating conditions. In addition, significant reductions in different environmental impact aspects (GWP, marine aquatic ecotoxicity, abiotic depletion and acidification) and LCC (minimum LCC value of around $€ 0.135$ per $\mathrm{m}^{3}$ ) can be achieved in comparison with other existing UWW treatment technologies.

\section{Acknowledgements}

This research work has been supported by the Spanish Ministry of Science and Innovation (MICINN, Project CTM2011-28595-C02-01/02) jointly with the European Regional Development Fund (ERDF) and Generalitat Valenciana (Project GVAACOMP2013/203), which are gratefully acknowledged.

\section{References}

Bank BEDEC - ITeC database, 2013. In Construmatica, Retrieved February 1, 2013, from http://www.construmatica.com/bedec

Barat, R., Serralta, J., Ruano, M.V., Jiménez, E., Ribes, J., Seco, A., Ferrer, J. 2012. Biological Nutrient Removal Model No 2 (BNRM2): A general model for Wastewater Treatment Plants. Water Science \& Technology 67, 1481-1489. 
Bombas Ideal S.A., 2013. Distribution Catalogue (Catálogo Distribución). In Bombas Ideal. Retrieved March 5, 2013 from http://www.bombas-ideal.com/pdf/CAT\%20C9\%20ES\%20\%5BD$100512 \% 5$ D.pdf.

Corominas, L., Foley, J., Guest, J.S., Hospido, A., Larsen, H.F., Morera, S., Shaw, A. 2013. Life cycle assessment applied to wastewater treatment: State of the art. Water research 47, 5480-5495.

Durán, F. 2013. Mathematical modelling of the anaerobic urban wastewater treatment including sulphate-reducing bacteria. Application to an anaerobic membrane bioreactor. Ph.D. thesis. Dept. of Hydraulic Engineering and Environment. Universitat Politècnica de València, Spain.

EPA, 2012. Environmental Protection Agency. Combined Heat and Power Partnership, Agency of the United States federal government.

Fenu, A., Roels, J., Wambecq, T., De Gussem, K., Thoeye, C., De Gueldre, G., Vand De Steene, B. 2010. Energy audit of a full scale MBR system. Desalination 262, 121-128.

Ferrer, J., Seco, A., Serralta, J., Ribes, J., Manga, J., Asensi, E., Morenilla, JJ., Llavador, F. 2008. DESASS: A software tool for designing, simulating and optimising WWTPs. Environmental Modelling \& Software. 23, 19-26.

Ferrer, J., Pretel, R., Durán, F., Giménez, J.B., Robles, A., Ruano, M.V., Serralta, J., Ribes, J., and Seco, A. 2015. Design methodology for anaerobic membrane bioreactors (AnMBR): A case study. Separation and Purification Technology 141, 378-386.

Foley, J., de Hass, D., Hartley, K., Lant, P. 2010.Comprehensive life cycle inventories of alternative wastewater treatment systems. Water Research 44, 1654-1666.

Gabarrón, S., Dalmaua, M., Porroa, J., Rodriguez-Rodaa, I., Comasa, J. 2015. Optimization of full-scale membrane bioreactors for wastewater treatment through a model-based approach. Chemical Engineering Journal 267, 34-42

Gallego, A., Hospido, A., Moreira, MT., Feijoo, G. 2008. Environmental performance of wastewater treatment plants for small populations. Resources, Conservation and Recycling 52, 931940.

Garrido-Baserba, M., Hospido, A., Reif, R., Molinos-Senante, M., Comas, J., Poch, M. 2013. Including the environmental criteria when selecting a wastewater treatment plant. Environmental Modelling \& Software 1-9. 
Giménez, J.B., Robles, A., Carretero, L., Durán, F., Ruano, M.V., Gattib, M.N., Ribes, J., Ferrer, J., Seco, A. 2011. Experimental study of the anaerobic urban wastewater treatment in a submerged hollow-fibre membrane bioreactor at semi-industrial scale. Bioresource Technology 102, 8799-8806.

Giménez J. B., Martí N., Ferrer J., Seco A. 2012. Methane recovery efficiency in a submerged anaerobic membrane bioreactor (SAnMBR) treating sulphate-rich urban wastewater: Evaluation of methane losses with the effluent. Bioresource Technology 118, 67-72.

Godin, D., Bouchard, C., Vanrolleghem, A. 2012. Net environmental benefit. Introducing a new LCA approach on wastewater treatment systems. Water Science and Technology 65.9, 1624-1631.

Hobson J. 2000. CH4 and N2O emissions from wastewater handling. In: Good practice guidance and uncertainty management in National Greenhouse Gas Inventories. Geneve, Switzerland: Intergovernmental Panel on Climate Change (IPCC) Publications.

Iberdrola S.A., 2013. Spanish electricity tariff (Tarifa eléctrica España). In Iberdrola. Retrieved March 5, 2013, from https://www.iberdrola.es/clientes/empresas/info/mercado-energetico.

ISO, 2006. International Organization for Standardization (ISO) 14040: Environmental Management - Life Cycle Assessment e Principles and Framework (Geneva).

Judd, S.J., Judd, C. 2011 Principles and Applications of Membrane Bioreactors in Water and Wastewater Treatment. Second Edition, Elsevier, London, UK.

Lin, H., Peng,W., Zhang,M., Chen,J., Hong,H., Zhang,Y. 2013. A review on anaerobic membrane bioreactors: Applications, membrane fouling and future perspectives. College of Geography and Environmental Sciences, Zhejiang Normal University, Jinhua, 321004, PR China. Desalination 314, $169-188$.

MAGRAMA, 2012. Official website of the Ministry of Agriculture, Food and Environment. Spanish government, Madrid. Survey land prices 2012. Retrieved May 5, 2014, from http://www.magrama.gob.es/es/estadistica/temas/estadisticasagrarias/Encuesta_Precios_Tierra_2012_tcm7-298705.pdf

MAGRAMA, 2015. Official website of the Ministry of Agriculture, Food and Environment. Spanish government, Madrid. Retrieved April 5, 2015, from http://www.magrama.gob.es/es/calidady-evaluacion-ambiental/temas/prevencion-y-gestion-residuos/flujos/lodos-depuradora/

Martinez-Sosa, D., Helmreich, B., Netter, T., Paris,S., Bischof, F., Horn, H. 2011. Anaerobic submerged membrane bioreactor (AnSMBR) for municipal wastewater treatment under mesophilic and psychrophilic temperature conditions, Bioresource Technol. 102 10377-10385. 
McCarty, P.L., Bae, J., Kim, J. 2011. Domestic wastewater treatment as a net energy producercan this be achieved? Environmental Science and Technology 45, 7100-7106.

Miliarium Aureum, S.L., (n.d.). Approximate cost of WWTP (Coste estimativo EDAR). In Miliarium.com - Ingeniería Civil y Medio Ambiente. Retrieved April 20, 2013, from http://www.miliarium.com/Proyectos/Depuradoras/introduccion/edar.asp.

Ozgun, H., Dereli, R.K., Ersahin, M.E., Kinaci, C., Spanjers, H., van Lier, J.B. 2013. A review of anaerobic membrane bioreactors for municipal wastewater treatment: Integration options, limitations and expectations. Separation and Purification Technology 118, 89-104.

Pretel, R., Robles, A., Ruano, M.V., Seco, A., Ferrer, J. 2013. Environmental impact of submerged anaerobic MBR (AnMBR) technology used to treat urban wastewater at different temperatures. Bioresource Technology 149, $532-540$.

Pretel, R., Robles, A., Ruano, M.V., Seco, A., Ferrer, J. 2015a. Filtration process cost in anaerobic membrane bioreactors (AnMBRs) for urban wastewater treatment. Separation Science and Technology. In Press.

Pretel, R., Shoener, B. D., Ferrer, J., Guest, J.S. 2015b. Navigating Environmental, Economic, and Technological Trade-Offs in the Design and Operation of Submerged Anaerobic Membrane Bioreactors (AnMBRs). Water Research. In Press, Corrected Proof.

Raskin, L. 2012. Anaerobic Membrane Bioreactors for Sustainable Wastewater Treatment. WERF Report U4R08, June 2012.

Robles, A., Ruano, M.V., García-Usach, F., Ferrer, J. 2012. Sub-critical filtration conditions of commercial hollow-fibre membranes in a submerged anaerobic MBR (HF-SAnMBR) system: The effect of gas sparging intensity. Bioresource Technology 114, 247-254.

Rodriguez-Garcia, G., Molinos-Senante, M., Hospido, A., Hernández-Sancho, F., Moreira, M.T., Feijoo, G. 2011. Environmental and economic profile of six typologies of wastewater treatment plants. Water Research. 45, 5997-6010.

Sainz-Lastre, J.A. 2005. Technologies for sustainability. Processes and unit operations in wastewater treatment (Tecnologías para la sostenibilidad. Procesos y operaciones unitarias en depuración de aguas residuales). Colección EOI Medio Ambiente. Madrid, Spain.

SIMEX., 2015. Distribution Catalogue in February 2015 (Catálogo Distribución). In SIMEX “soluciones hidráulicas integrales” Retrieved February 25, 2015 from http://www.simexco.com.mx/productos/precios.pdf 
Smith, A. L., Skerlos, S.J., Raskin, L. 2013. Psychrophilic anaerobic membrane bioreactor treatment of domestic wastewater. Water research 47, 1655-1665

Smith, A.L., Stadler, L.B., Cao, L, Love, N.G., Raskin, L, Skerlos, S.J. 2014. Navigating Wastewater Energy Recovery 1 Strategies: A Life Cycle Comparison of Anaerobic Membrane Bioreactor and Conventional Treatment Systems with Anaerobic Digestion. Environmental Science \& Technology 48, 5972-5981.

Stuckey, D.C. 2012. Recent developments in anaerobic membrane reactors. Bioresource Technology 122, 137-148.

Visvanathan, C., Aim, R. B., Parameshwaran, K. 2000. Membrane separation bioreactors for wastewater treatment. Environmental Science and Technology 30, 1-48. 


\section{Table and Figure captions}

Table 1. (a) Characteristics of the UWW entering the WWTP; (b) main operating parameter values in CAS, AeMBR and AnMBR units; and (c) main operating parameter values in CAS- and AeMBR-based post-treatment unit. Nomenclature: SRT: Sludge retention time; MLSS: mixed liquor suspended solids concentration in the reaction volume; $\mathbf{J}_{\mathbf{2 0}}: 20^{\circ} \mathrm{C}$-standardised transmembrane flux; $\mathbf{S}(\mathbf{A} / \mathbf{G}) \mathbf{D}_{\mathbf{m}}$ : specific air/gas demand per $\mathrm{m}^{2}$ of membrane area. * Judd \& Judd, 2011; ** Pretel et al., $2015 a$.

Table 2. Factors affecting the investment cost of the proposed UWW treatment schemes (CAS, AeMBR and AnMBR), including construction work and equipment.

Figure 1. Process flow diagram of the proposed UWW treatment schemes for nutrient removal: (a) *CAS and **AeMBR, and (b) AnMBR (*AnMBR+CAS, *AnMBR+CAS ${ }_{\mathrm{CH} 4 \mathrm{DNN}}, * * A n M B R+A e M B R$, and **AnMBR+AeMBR ${ }_{\mathrm{CH} 4 \mathrm{DN}}$,). AnT is not considered in Scenario 2: chemical removal of phosphorus. Nomenclature: $\mathbf{A B}$ : Air Blower; AD: Anaerobic Digester; AeT: Aerobic tank; AnR: Anaerobic Reactor; AnT: Anaerobic tank; AxT: Anoxic tank; CHP: Combined Heat and Power; DS: Dewatering System; GB: Gas Blower; HE: Heat Exchanger; MT: Membrane Tank; PS: Primary Settler; PT: Pre-treatment; SS: Secondary Settler; and TS: Thickening System.

Figure 2. Energy balance of CAS, AeMBR and AnMBR (AnMBR+AeMBR, AnMBR+AeMBR ${ }_{\mathrm{CH} 4 \mathrm{DN}}$, AnMBR+CAS, AnMBR+CAS ${ }_{\mathrm{CH} 4 \mathrm{DN}}$ ) for nutrient removal. Scenario 1: biological and chemical removal of phosphorus; and Scenario 2: chemical removal of phosphorus.

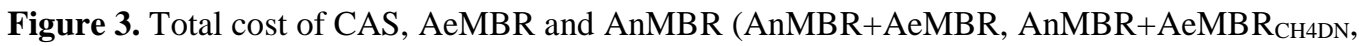
AnMBR+CAS AnMBR+CAS $\mathrm{CH}_{\mathrm{CDN}}$ ) for nutrient removal. Bars represent a discount rate of $10 \%$. Scenario 1: biological and chemical removal of phosphorus; and Scenario 2: chemical removal of phosphorus.

Figure 4. Effect of $\mathrm{J}_{20}\left(\%\right.$ of critical flux: 80-120) and $\mathrm{SGD}_{\mathrm{m}}\left(0.05-0.3 \mathrm{~m}^{3} \cdot \mathrm{m}^{-2} \cdot \mathrm{h}^{-1}\right)$ on AnMBR cost. Bars represent the baseline of the proposed UWW treatment schemes (in case of AnMBR: SGD $0.1 \mathrm{~m}^{3} \cdot \mathrm{m}^{-2} \cdot \mathrm{h}^{-1}$ and J105\%). Scenario 1: biological and chemical removal of phosphorus; and Scenario 2: chemical removal of phosphorus.

Figure 5. Weighted average distribution of the impacts of the factors considered in the inventory analysis through: (a) marine aquatic ecotoxicity; (b) GWP; and (c) abiotic depletion. Scenario 1: biological and chemical removal of phosphorus; and Scenario 2: chemical removal of phosphorus.

Figure 6. LCA results of the proposed UWW treatment schemes expressed as: (a) weighted average 
distribution, and (b) percentage (\%). Method: CML 2 baseline 2000 V2.05 / West Europe, 1995 / normalisation / excluding infrastructure processes / excluding long-term emissions. Scenario 1: biological and chemical removal of phosphorus; and Scenario 2: chemical removal of phosphorus. 
Table 1.

\begin{tabular}{llc}
\hline Parameter & Unit & Value \\
\hline $\mathrm{T}-\mathrm{COD}$ & $\mathrm{mg} \mathrm{COD} \cdot \mathrm{L}^{-1}$ & 945 \\
\hline $\mathrm{T}-\mathrm{BOD}$ & $\mathrm{mg} \mathrm{COD} \cdot \mathrm{L}^{-1}$ & 715 \\
\hline $\mathrm{VFA}$ & $\mathrm{mg} \mathrm{VFA} \cdot \mathrm{L}^{-1}$ & 45 \\
\hline $\mathrm{TN}$ & $\mathrm{mg} \mathrm{N} \cdot \mathrm{L}^{-1}$ & 47 \\
\hline $\mathrm{NH}_{4}-\mathrm{N}$ & $\mathrm{mg} \mathrm{N} \cdot \mathrm{L}^{-1}$ & 16 \\
\hline $\mathrm{TP}$ & $\mathrm{mg} \mathrm{P} \cdot \mathrm{L}^{-1}$ & 13 \\
\hline $\mathrm{PO}_{4}-\mathrm{P}$ & $\mathrm{mg} \mathrm{P} \cdot \mathrm{L}^{-1}$ & 4 \\
\hline $\mathrm{SO}_{4}-\mathrm{S}$ & $\mathrm{mg} \mathrm{S} \cdot \mathrm{L}^{-1}$ & 10 \\
\hline $\mathrm{TSS}$ & $\mathrm{mg} \mathrm{TSS} \cdot \mathrm{L}^{-1}$ & 429 \\
\hline $\mathrm{VNSS}$ & $\mathrm{mg} \mathrm{VNSS} \cdot \mathrm{L}^{-1}$ & 100 \\
\hline Alkalinity & $\mathrm{mg} \mathrm{CaCO} \cdot \mathrm{L}^{-1}$ & 350 \\
\hline
\end{tabular}

(a)

\begin{tabular}{lcccccc}
\hline Technology & $\begin{array}{c}\text { SRT } \\
(\mathbf{d a y s})\end{array}$ & $\begin{array}{c}\text { MLSS } \\
\left(\mathbf{g}^{-} \mathbf{L}^{-1}\right)\end{array}$ & $\begin{array}{c}\mathbf{J}_{\mathbf{2 0}} \\
\left(\mathrm{L} \cdot \mathrm{m}^{-2} \cdot \mathrm{h}^{-1}\right)\end{array}$ & $\begin{array}{c}\mathbf{S}(\mathbf{A} / \mathbf{G}) \mathbf{D}_{\mathbf{m}} \\
\left(\mathbf{m}^{\mathbf{3}} \cdot \mathbf{m}^{-2} \cdot \mathbf{h}^{-1}\right)\end{array}$ & $\begin{array}{c}\text { Sludge } \\
\text { stabilisation }\end{array}$ & $\begin{array}{c}\text { Tertiary } \\
\text { treatment }\end{array}$ \\
\hline CAS & 10 & 2.3 & & & AD & UV \\
\hline AeMBR & 10 & 6.5 & $14 *$ & $0.3 *$ & AD & N.A. \\
\hline AnMBR & 40 & 11 & $20 * *$ & $0.1 * *$ & N.A. & N.A. \\
\hline
\end{tabular}

(b)

\begin{tabular}{lccccc}
\hline Post-treatment Technology & $\begin{array}{c}\text { SRT } \\
(\text { days })\end{array}$ & $\begin{array}{c}\text { MLSS } \\
\left(\mathbf{g} \cdot \mathbf{L}^{-1}\right)\end{array}$ & $\begin{array}{c}\mathbf{J}_{\mathbf{2 0}} \\
\left(\mathrm{L} \cdot \mathrm{m}^{-2} \cdot \mathrm{h}^{-1}\right)\end{array}$ & $\begin{array}{c}\mathbf{S}(\mathbf{A} / \mathbf{G}) \mathbf{D}_{\mathbf{m}} \\
\left(\mathbf{m}^{\mathbf{3}} \cdot \mathbf{m}^{-2} \cdot \mathbf{h}^{-\mathbf{1}}\right)\end{array}$ & $\begin{array}{c}\text { Tertiary } \\
\text { treatment }\end{array}$ \\
\hline CAS & 10 & 2.3 & & & UV \\
\hline AeMBR & 10 & 2.6 & $29 *$ & $0.3 *$ & N.A. \\
\hline & & $(\mathbf{c})$ & & &
\end{tabular}


Table 2.

\begin{tabular}{|c|c|c|c|c|c|c|}
\hline & CAS & AeMBR & $\begin{array}{c}\text { AnMBR+ } \\
\text { AeMBR }\end{array}$ & $\begin{array}{c}\text { AnMBR+ } \\
\text { AeMBRCH4DN }\end{array}$ & $\begin{array}{c}\text { AnMBR+ } \\
\text { CAS }\end{array}$ & $\begin{array}{l}\operatorname{AnMBR+} \\
\text { CAS }_{\mathrm{CH} 4 \mathrm{DN}}\end{array}$ \\
\hline \multicolumn{7}{|l|}{ CONSTRUCTION } \\
\hline Primary settler & $\sqrt{ }$ & $\checkmark$ & & & & \\
\hline Secondary settler & $\sqrt{ }$ & & & & $\checkmark$ & $\sqrt{ }$ \\
\hline Thickener & $\sqrt{ }$ & $\sqrt{ }$ & & & & \\
\hline Anaerobic reactor & & & $\checkmark$ & $\checkmark$ & $\checkmark$ & $\checkmark$ \\
\hline Membrane tank & & $\sqrt{ }$ & $\checkmark$ & $\sqrt{ }$ & $\checkmark$ & $\sqrt{ }$ \\
\hline Anaerobic digester & $\sqrt{ }$ & $\sqrt{ }$ & & & & \\
\hline CIP (clean-in-place) tank & & $\sqrt{ }$ & $\sqrt{ }$ & $\sqrt{ }$ & $\checkmark$ & $\checkmark$ \\
\hline Equalisation tank & & $\sqrt{ }$ & $\checkmark$ & $\checkmark$ & $\checkmark$ & $\checkmark$ \\
\hline AO/A2O reactor & $\sqrt{ }$ & $\sqrt{ }$ & $\sqrt{ }$ & $\sqrt{ }$ & $\checkmark$ & $\sqrt{ }$ \\
\hline Land needed & $\sqrt{ }$ & $\sqrt{ }$ & $\sqrt{ }$ & $\sqrt{ }$ & $\checkmark$ & $\sqrt{ }$ \\
\hline \multicolumn{7}{|l|}{ EQUIPMENT } \\
\hline Pumping equipment & $\sqrt{ }$ & $\sqrt{ }$ & $\checkmark$ & $\sqrt{ }$ & $\checkmark$ & $\sqrt{ }$ \\
\hline Piping/valve system & $\checkmark$ & $\checkmark$ & $\checkmark$ & $\sqrt{ }$ & $\checkmark$ & $\sqrt{ }$ \\
\hline $\begin{array}{l}\text { Aeration devices } \\
\text { (diffusers) }\end{array}$ & $\sqrt{ }$ & $\checkmark$ & $\sqrt{ }$ & $\checkmark$ & $\checkmark$ & $\checkmark$ \\
\hline Air cleaning equipment & $\sqrt{ }$ & $\sqrt{ }$ & $\sqrt{ }$ & $\sqrt{ }$ & $\checkmark$ & $\sqrt{ }$ \\
\hline Stirrers & $\sqrt{ }$ & $\sqrt{ }$ & $\sqrt{ }$ & $\sqrt{ }$ & $\checkmark$ & $\sqrt{ }$ \\
\hline Rotofilter & & $\checkmark$ & $\checkmark$ & $\sqrt{ }$ & $\checkmark$ & $\checkmark$ \\
\hline Dewatering system & $\sqrt{ }$ & $\sqrt{ }$ & $\checkmark$ & $\sqrt{ }$ & $\checkmark$ & $\sqrt{ }$ \\
\hline $\begin{array}{l}\text { Ultrafiltration hollow-fibre } \\
\text { membranes }\end{array}$ & & $\sqrt{ }$ & $\sqrt{ }$ & $\sqrt{ }$ & $\sqrt{ }$ & $\sqrt{ }$ \\
\hline $\begin{array}{l}\text { Circular suction scraper } \\
\text { bridges for primary settler }\end{array}$ & $\sqrt{ }$ & $\sqrt{ }$ & & & & \\
\hline $\begin{array}{l}\text { Circular suction scraper } \\
\text { bridges for secondary } \\
\text { settler }\end{array}$ & $\sqrt{ }$ & & & & $\sqrt{ }$ & $\sqrt{ }$ \\
\hline $\begin{array}{l}\text { Circular suction scraper } \\
\text { bridges for thickener }\end{array}$ & $\sqrt{ }$ & $\sqrt{ }$ & & & & \\
\hline UV radiation system & $\checkmark$ & & & & & \\
\hline CHP system & $\sqrt{ }$ & $\checkmark$ & $\sqrt{ }$ & $\sqrt{ }$ & $\sqrt{ }$ & $\sqrt{ }$ \\
\hline $\begin{array}{l}\text { Degassing membrane } \\
\text { system }\end{array}$ & & & $\checkmark$ & & $\checkmark$ & \\
\hline
\end{tabular}



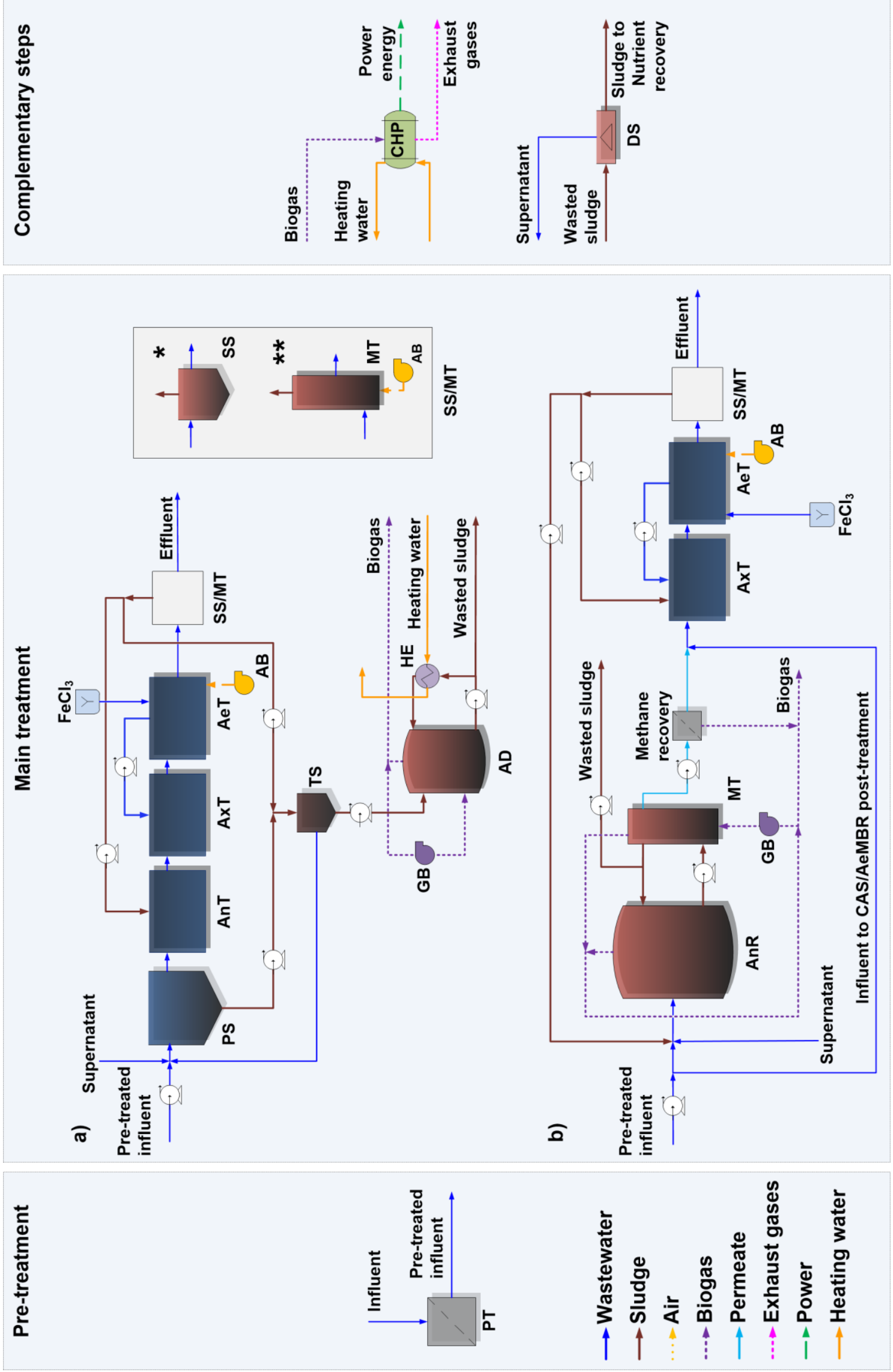

Figure 1. 


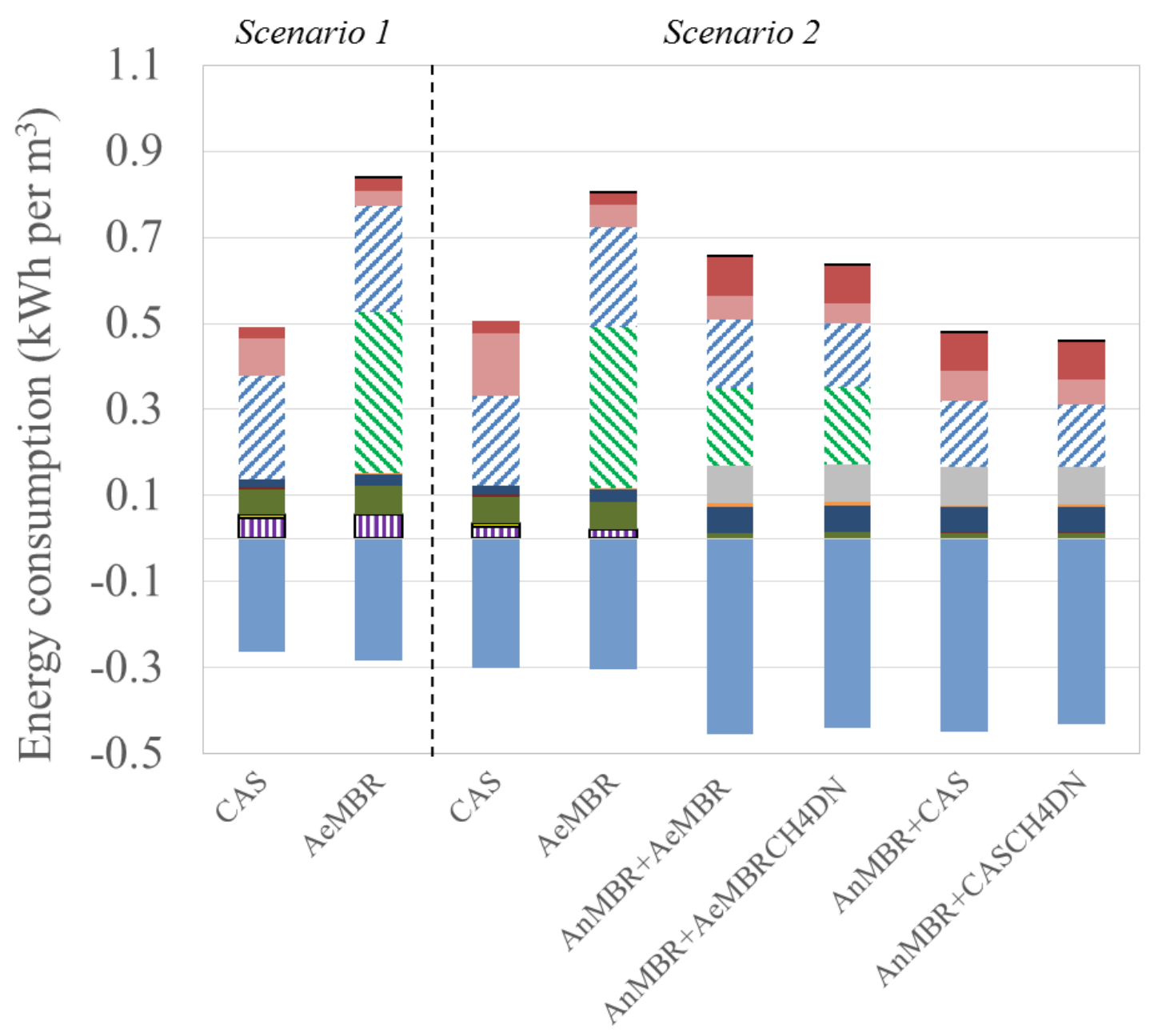

- Rotofilter

- Anaerobic digester / reactor stirring

- $\mathrm{AO} / \mathrm{A} 2 \mathrm{O}$ reactor stirring \& Equalisation tank stirring (blower)

- Air pumping

$\checkmark$ Membrane scouring by air sparging

Membrane scouring by gas sparging

Permate pumping

- Rest of pumping system

- Settling

- Sludge thickening and dewatering

$\square \mathrm{UV}$ radiation

mNet heat energy demand (digester)

a Power energy recovery from methane

Figure 2. 


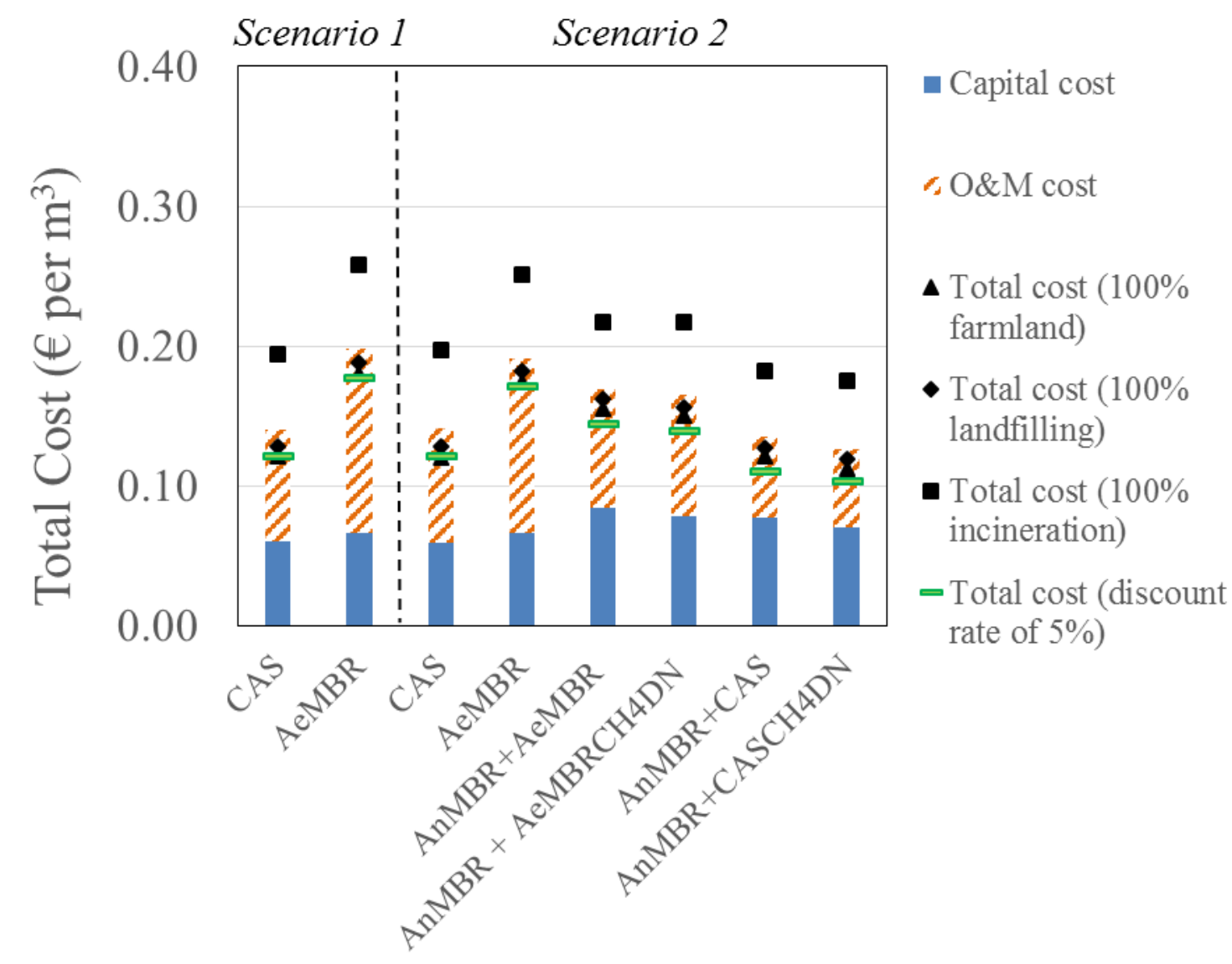

Figure 3. 


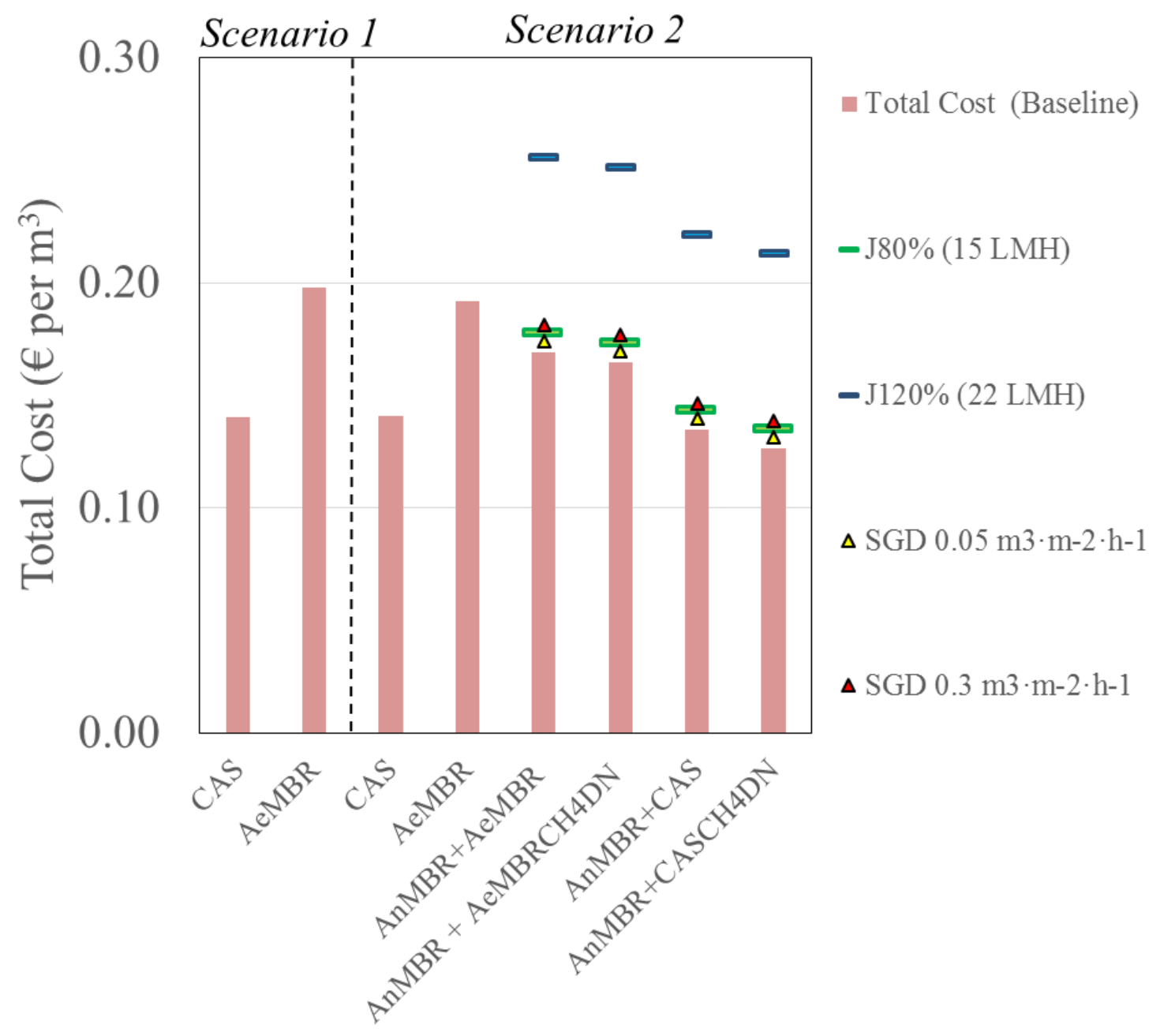

Figure 4. 


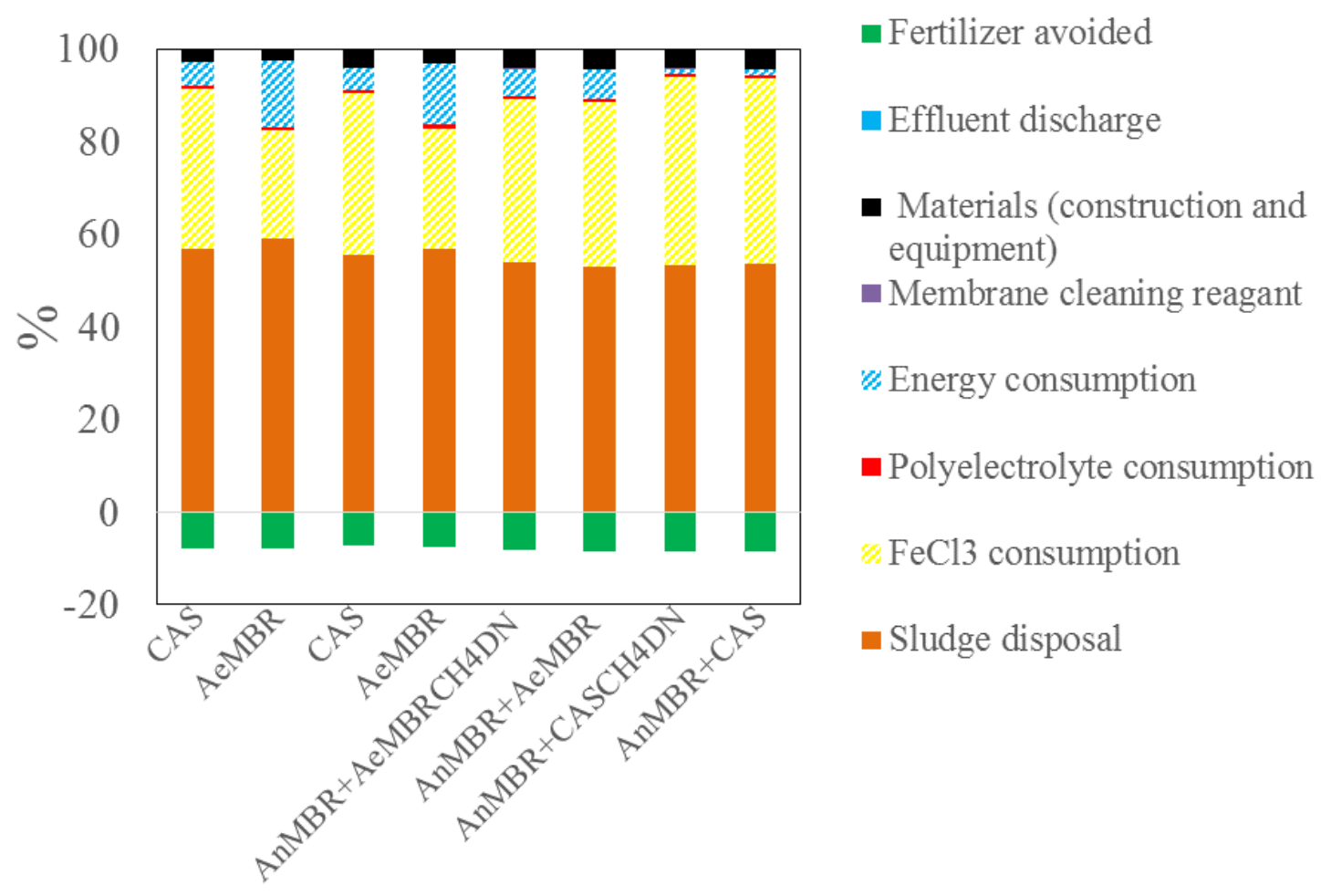

(a)

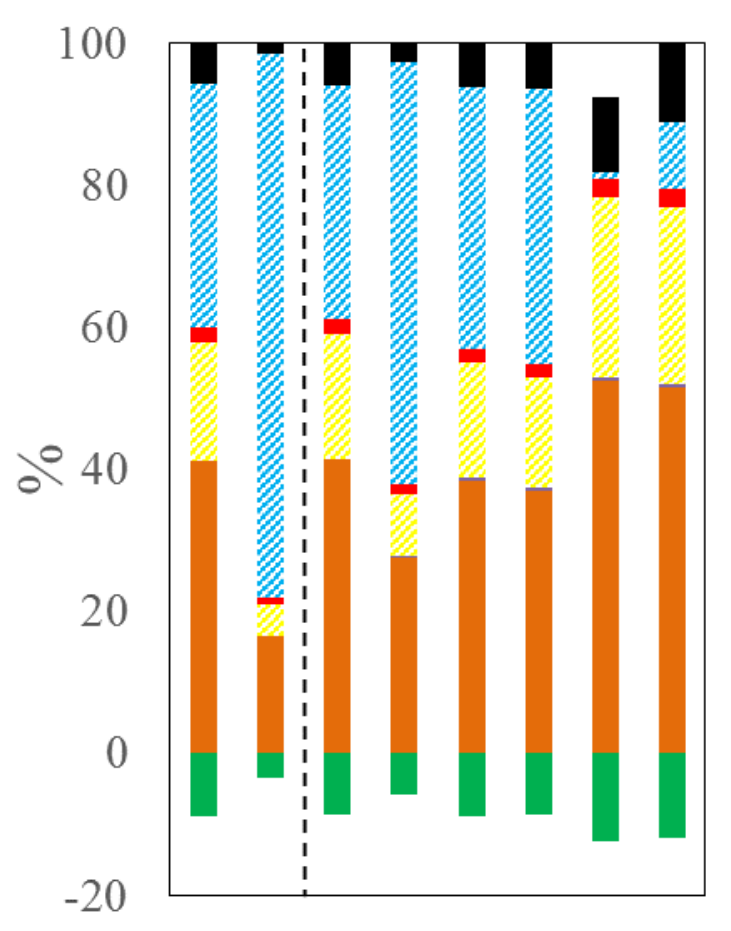

(b)

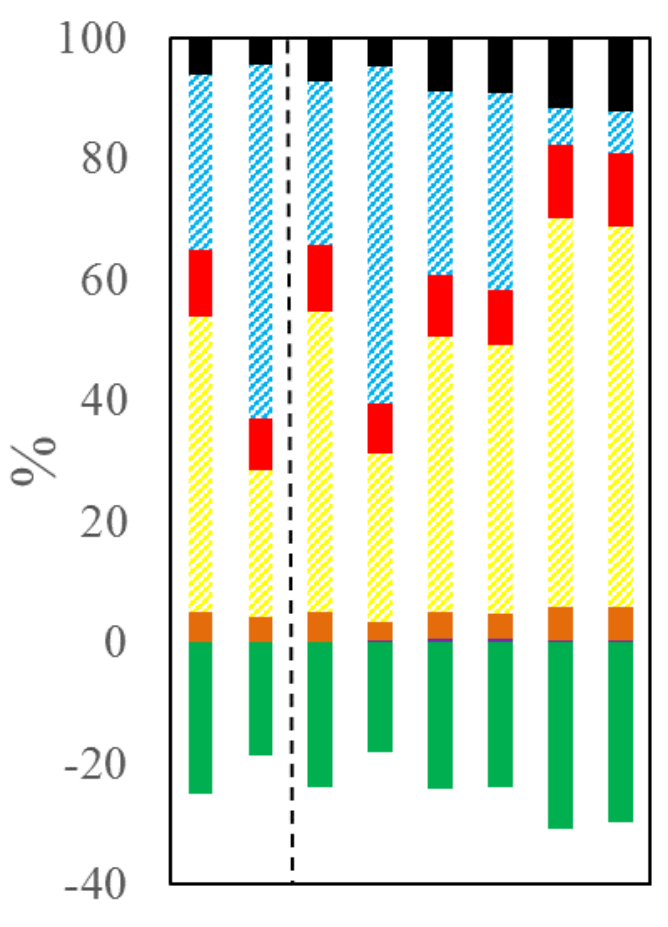

(c)

Figure 5. 


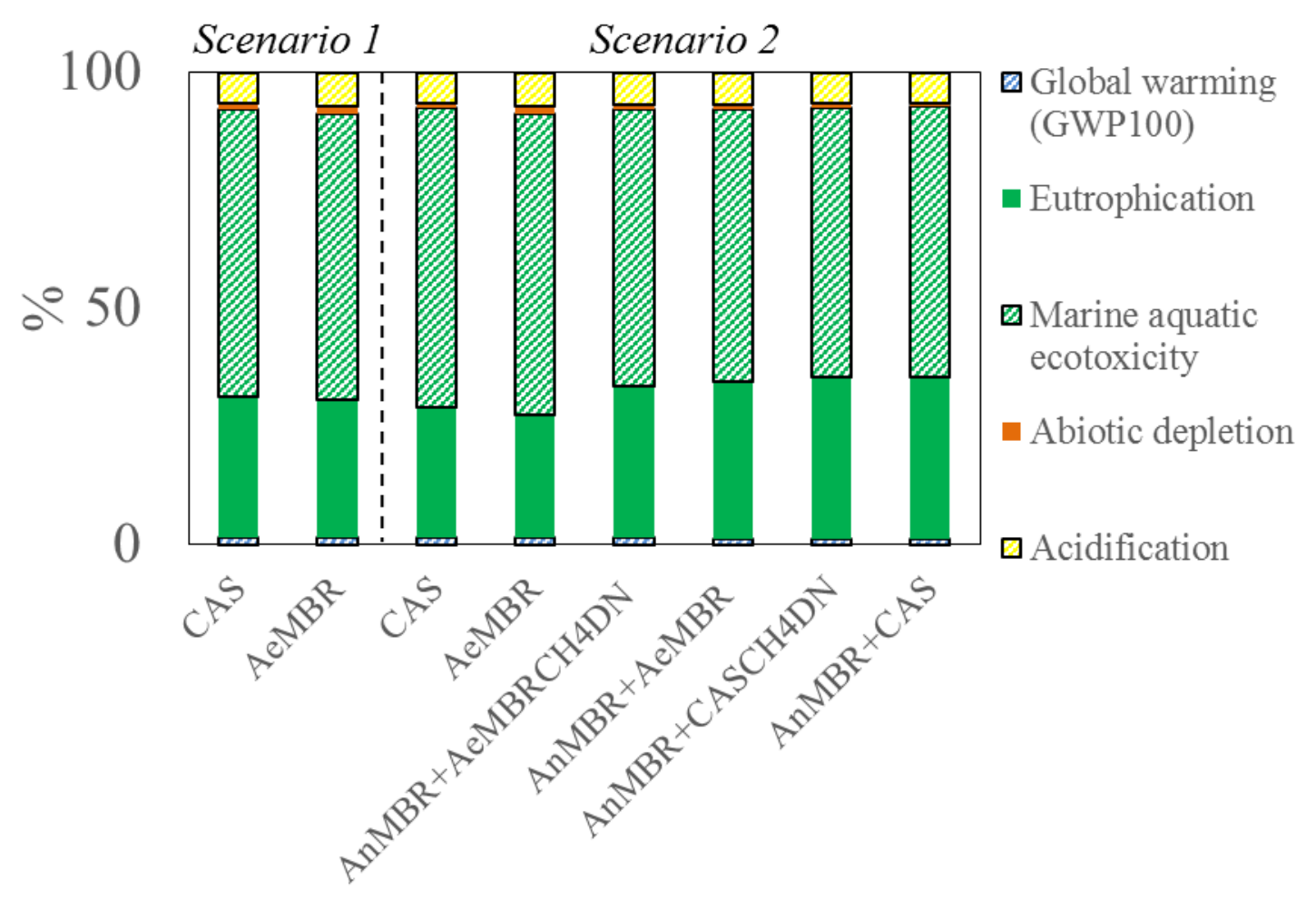

(a)

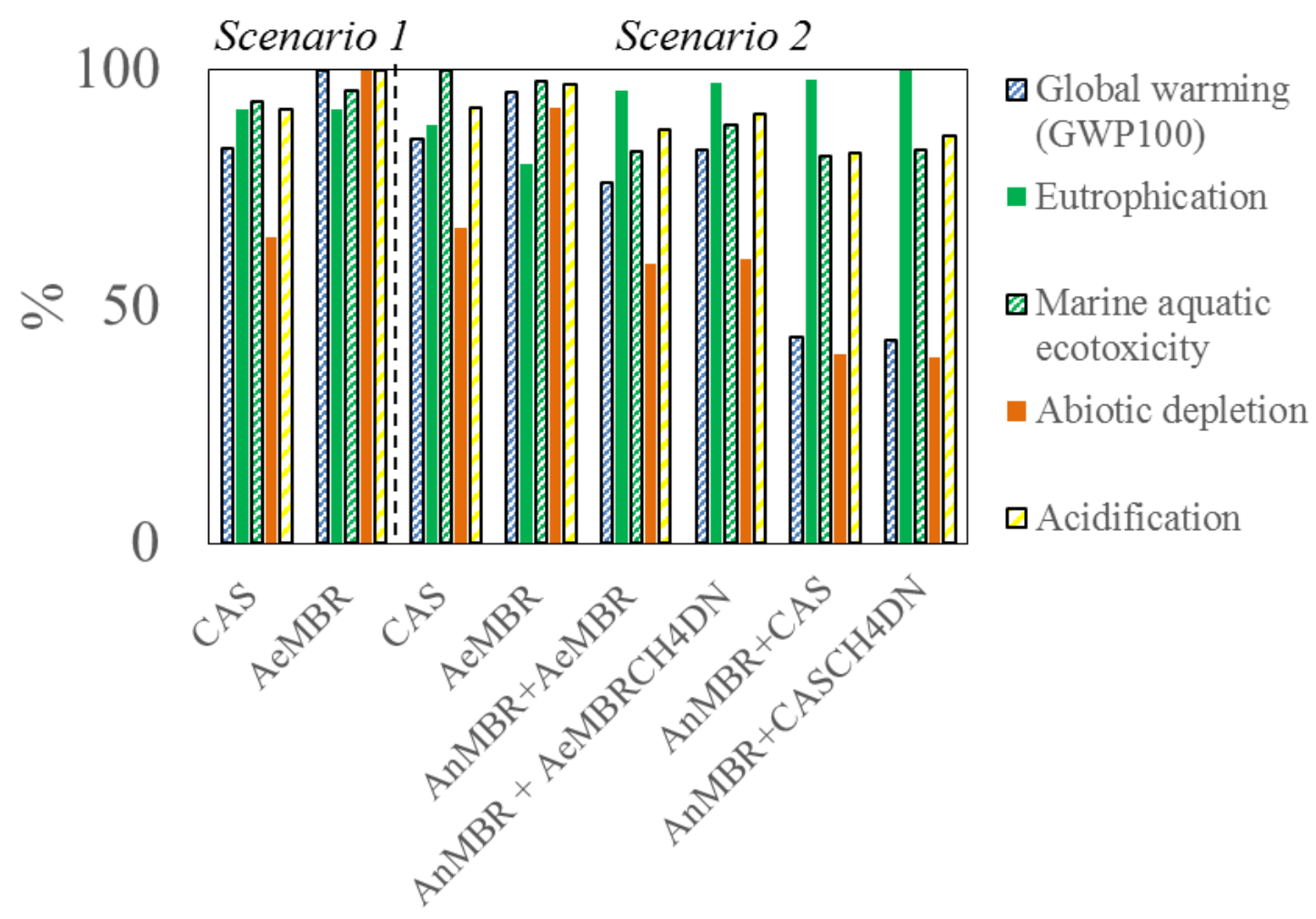

(b)

Figure 6. 